\title{
The effect of constructive learning method according to a pattern of brain control on the level of the motor sentence performance in exercises \\ "Dr/Ali mostafa Ghalab
}

Introduction and research problem

Sprot Exercise are one of the activities that require their practitioners to have a high degree of neuromuscular compatibility and agility in addition to a high degree of creativity and innovation, whether at the mental level or at the motor level, and is linked to optimal performance, using the left and right side of the brain in a controlled manner that dominates the motor balance in Different directions. During the past two decades, educational research has witnessed a major shift in its view of the processes of teaching and learning, which means that they are the ideas that seize the learner to form new experiences, and learning occurs when the ideas that the learner possesses are modified or new information is added, and this means that constructivism is based on external factors that affect In the learner's learning, such variables are the teacher (his personality - his enthusiasm his enhancement - the learning environment - the curriculum learning outcomes . (4: 17)

The learning technology has necessitated consideration of the learning method, which achieves specific educational goals, and which focuses on the learner, so that it becomes active in finding, getting and practicing, and the role of the teacher in this strategy is the guide who helps the learner in setting goals and prepares learning resources for him. Therefore .. Today's teacher is a teacher. And an athlete and does not stop at a specific style in teaching. ( $(Y: T V)$

The constructive learning method is considered one of the most prominent models that depend on constructive thought through the four stages (advocacy, discovery and exploration, suggesting interpretations and solutions, taking action). Community mastery .(10:8)

"Lecturer in the Department of Gymnastics, Exercises, Kinetic Expression and Sports Shows - Faculty of Physical Education, Tanta University

Assiut Journal For Sport Science Arts 
Constructive learning is considered one of the most innovative models in practical education during the past years, and it will be the most effective means of linking the various channels in research in practical education. $(5: 338)$

this depends on the success of the teaching method on the teacher and the learner and the ability of each of them to understand the other and respond to them. (6:56)

It can be said that the constructive learning method is one of the learner-centered teaching methods rather than being centered around the teacher, and it is worth noting that the constructive learning method seeks to learn new knowledge through building it themselves, and this learning is meaningful for them and closely related to their practical life. It also seeks to develop learners' ability to self-learning through the development of learning processes from or scientific research they have, including (processes of observation- comparison generalization- conclusion). (4: 348)

The structural approach to learning supports open experiences, although they are somewhat close to cognitive, in some aspects, including the similarity between the processes of the mind and computer operations, and the biologist has added an information processor, which is not just an organizer of information, but a flexible user of it through the education process. (11:15)

This helps the kinesthetic learning learner to obtain appropriate responses and build and consolidate the apparent structure of the movement, and then reach the goal drawn with precision, noting the use of its requirements that lead to an increase and speed of learning, including the use of auxiliary tools as well as assistive devices as well as the use of appropriate feedback for the type of The nature of the skill or activity that means carrying out the reinforcement process in order to reach the goals. (1:52)

In this regard, "AbdelRahim, Abdel-Nasser" (2010) mentions that learning mathematical skills is one of the aspects that are directly related to the central nervous system, and that it requires the brain to be employed in an integrated manner for the differences and functions of the 
spherical hemispheres of the human brain. The topic of cerebral control is one of the vital topics. Related to thinking and learning styles. (7: 260)

On the other hand, there are differences between the spherical hemispheres of the brain in a number of higher mental functions, the left spherical hemisphere performs verbal, analytical and logical functions, while the right spherical hemisphere specializes in perceiving and remembering patterns of sensory and visual responses and thinking patterns that lead to creativity, as the functions associated with intuition and emotion are concentrated in it. And sentiment, creativity, art and the use of imagination, and we find that there are jobs performed by one of the two hemispheres better than the other half, and therefore the concept of control is used to express the division of labor between the two spherical halves. $(2: 16,17)$

Brain control is considered one of the factors contributing to the educational process, especially if we know that the study environment has been designed to affect the different educational methods of students, and it has been shown that teachers prefer a certain type of education over other types and recognize that the teaching methods have a left hemisphere, and this means The left hemisphere is preferred by students in the teaching and learning process at the expense of a clear neglect in developing the functions of the right side of the brain. (19:18)

The concept of brain control refers to the scientist John Jackson with his idea of the leading side in the brain (The Leading Hemisphere), and this concept is considered the origin from which the concept of brain control was derived. As Jackson puts it, the two hemispheres of the brain cannot just be repeating each other. As he showed that the damage that occurs to one of the two hemispheres of the brain loses the ability to speak, which is the highest function in a person, then it is necessary that one of the two hemispheres of the brain be the one that assumes the highest of these functions, and thus this half is the leading half. This is also confirmed by Hugoliepman, a neuroscientist, who referred to the left hemisphere's control in most individuals, as he showed that 
the left hemisphere is the one that controls voluntary movements, language, and logic, and thus the concept of brain control emerged, which came to refer to the distinction of one of the spherical hemispheres. The brain has control over the individual's behavior, or the individual's tendency to depend on one hemisphere of the brain more than the other. After the concept of cerebral control became popular, it soon appeared that the right hemisphere is the neglected half, and this result was confirmed by the neuroscientist Joseph Bougon: he believes that the current trend in education focuses on the functions of the left side of the brain, and this leads to the lack of growth of side functions Right brain (18: 3).

Jensen (2001) states that individuals who are described as controlling the right thinking pattern are responding to visual and kinesthetic instructions better than verbal instructions, expressing their feelings and emotions openly, and prefer to deal with a large number of problems at the same time. Individuals who are described as controlling the thinking style are characterized by Right, they respond to verbal instructions better than motor and visual, and are able to express their emotions and feelings, and prefer to deal with one problem at the same time, and the individuals of this complementary pattern are distinguished by their ability to use the left and right hemispheres of the brain together in learning and thinking and in carrying out mental tasks. $(85: 15)$

There are many methods and methods for learning skills, including exercises with tools, which require moving more than one part of the different parts of the body at the same time and in many different directions. It also helps in developing some of the physical characteristics on which athletic performance depends, such as muscle capacity, kinesthetic compatibility, speed and agility. (16:27)

Exercise programs allow the use of tools and devices that play an important role in strengthening muscles and raising the level of muscular capacity, which is considered one of the most important physical and movement capabilities, as well as the harmonic abilities that affect 
the level of performance in various sports activities (13: 129)

$$
\text { "Khattab, Attiyat" }
$$

(2006) also indicates that exercises with tools increase the degree of enthusiasm of the players and their willingness to practice, increase motivation and improve their level of fitness, as exercises with the rope are distinguished by its great contribution to improving the work of internal organs and in raising the general level of the player's ability and the rope is used to a large extent in sports activities that perform With force and speed (9:24)

Loran and peter ferancais (1990) indicate that one of the tools used in training is the step aerobic box or training box, which is considered one of the training methods, which depend on moving up and down to and from a box, controlling and controlling performance against and with the Earth's gravity in perfect agreement between Work of the upper, lower, right and left limbs of the body. (17: 114)

Dibi, p, scott, R (1996) mentions the stepping box: a bench step is a platform in the form of a rectangular box with two dimensions $(60 \mathrm{~cm}$ long, $35 \mathrm{~cm}$ wide) or (75 cm length, $35 \mathrm{~cm}$ wide) or (90 cm length,
$35 \mathrm{~cm}$ ). Width $\mathrm{cm}$ ) and of various heights made of a strong material such as reinforced plastic or fiberglass to bear the weight and movement of the body and at the same time it has a degree of flexibility to allow to absorb shocks that fall on the knee and ankle joints as a result of up and down (14: 75)

The harmonic abilities are considered the basic component of reaching the athlete to the sports form, as it is the backbone for developing the technical skills of each sport, so mastering the movement skills in accordance with the required compatibility is necessary for the movement to be performed in its proper framework in terms of strength, speed and time required for it, and it plays the integrity of interconnectedness. Between the nervous and muscular systems, and the efficiency of the nervous system in controlling nerve signals the decisive role in the efficiency of these abilities, as these signals are sent simultaneously or in rapid succession to more than one part of the body so that the movement takes place in the appropriate timing and in the desired directions. (8: 131 136). 
In this regard, "AbdelRahim, Abdel-Nasser" (2010) stated that learning mathematical skills is one of the aspects that are directly related to the central nervous system, and that it requires the brain to be employed in an integrated manner for the differences and functions of the spherical hemispheres of the human brain, and the issue of hemispheric dominance is one of the vital topics that It has a link to thinking and learning styles. (7: 260)

There is also another training tool that contributes greatly to improving some important physical variables, which is the Jump-Rope, which is considered one of the forms of good physical exercises that can achieve the development of many physical abilities such as agility, compatibility, movement ability and physical fitness. (3: 6)

Irem duzgun, gul baltaci et all (2010) stresses the importance of jumping with training ropes that exercise using jump ropes plays an important role in the integration of skill performance, working on the link between the muscular and nervous systems, as well as improving agility and muscular capacity, which are important elements in skill performance In various sports activities. (3:29)

This, and through the teaching experience of the researcher for the exercise course for specialization students, he noticed that there is no kinematic link between the right-side movements and the left-side movements among students of the physical exercise specialization at the Faculty of Physical Education, Tanta University, the researcher noticed that there are some students that belong to the category of unilateral brain control (right) The thing that makes them distinguished in the performance of the motor sentence of exercises in one direction in a distinctive way. We showed the other direction. It lacks some elements associated with harmonic abilities such as the motor and rhythmic linkage and others, which negatively affects the level of performance in the left and right directions and on both sides of the body, and within the limits of the researcher's access to studies And the previous references have reached the importance of using the structural method in 
learning programs, as well as the importance of using different tools in developing the pattern of brain control, which prompted the researcher to identify the effect of the structural method in learning according to the pattern of brain control on the harmonic abilities and the level of the motor sentence performance of students of the major Exercises.

\section{research aims :}

The research aims to identify the effect of using the constructive learning method according to the type of brain control on the level of the motor sentence performance in exercises through: -

1- The harmonic capabilities leve .

2- The performance level of exercises (under discussion).

Research hypotheses :

- There are statistically significant differences between the two types of cerebral control (right, left) for the research sample in the premeasurement, while there are no differences between them in the post measurement.

- There are statistically significant differences between the pre-measurement and the post-measurement in the research sample, in terms of harmonic abilities and the level of performance of the set of exercises in favor of the postmeasurement.

\section{Search terms:}

\section{- Cerebral control pattern}

It is the distinction of one of the spherical hemispheres of the brain to control the behavior of the individual or the tendency of the individual to depend on one hemisphere of the brain more than the other. (7: 9)

\section{Harmonic capabilities:}

"A visual external manifestation of the processes of controlling and regulating motor activity in the central nervous system" and it includes many interconnected abilities (the ability to balance - the ability to control movement the ability to change direction the ability to assess posture the ability to connect motor, rhythmic ability). (Procedural definition)

\section{Search procedures:}

\section{-Research Methodology:}

The researcher used the experimental approach to suit the nature of the research, and one of the experimental designs was used, which is the experimental design of one group using pre and post measurement. 
Research Community and Sample:

The study population included students of exercises in the Faculty of Physical Education, Tanta University, in the academic year 2018/2019, the researcher selected the study sample in an intentional manner, and the total number of the basic research sample reached (20) students, and (9) students were used as an exploratory sample And from outside the main sample and within the research community to conduct.

Moderation of sample distribution in the tests under consideration:-

Table (1)

The mean, standard deviation, and skew factor of growth rates , tests of harmonic capabilities and level of performance are under consideration $\mathrm{N}=\mathbf{2 0}$

\begin{tabular}{|c|c|c|c|c|c|}
\hline \multicolumn{2}{|c|}{ Variables } & $\begin{array}{c}\text { measruing } \\
\text { unit }\end{array}$ & Mean & $\begin{array}{l}\text { Standard } \\
\text { deviation }\end{array}$ & skewness \\
\hline \multirow{3}{*}{$\begin{array}{l}\text { Growth } \\
\text { rates }\end{array}$} & Age & Year & 18.54 & 1.54 & 1.84 \\
\hline & Height & $\mathrm{Cm}$ & 178.62 & 2.61 & 0.31 \\
\hline & Weight & $\mathrm{Kg}$ & 67.37 & 5.72 & 1.49 \\
\hline \multirow{5}{*}{ 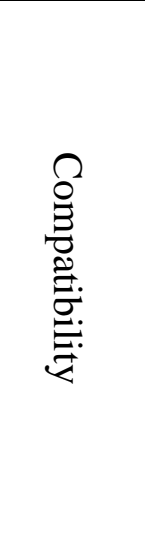 } & $\begin{array}{c}\text { assess } \\
\text { situations }\end{array}$ & Degree & 4.12 & 0.84 & 1.75 \\
\hline & $\begin{array}{c}\text { Dynamic } \\
\text { link }\end{array}$ & Accurate & 2.25 & 0.49 & -0.84 \\
\hline & $\begin{array}{c}\text { maintain } \\
\text { balance }\end{array}$ & Degree & 19.24 & 2.93 & 1.19 \\
\hline & $\begin{array}{c}\text { Rhythmic } \\
\text { ability }\end{array}$ & Degree & 46.17 & 1.16 & 0.67 \\
\hline & $\begin{array}{l}\text { adapt to } \\
\text { changing } \\
\text { situations }\end{array}$ & Degree & 45.53 & 2.17 & 0.34 \\
\hline \multicolumn{2}{|c|}{$\begin{array}{l}\text { The level of } \\
\text { performance of the } \\
\text { whole exercise }\end{array}$} & Degree & 5.25 & 1.94 & 1.57 \\
\hline
\end{tabular}

It is clear from Table (1) that:

- The torsion coefficients of the research sample in the variables under investigation

ranged between $(0.84-1.84)$, meaning that they were confined to $(-3,+3)$ and thus 
they fall within the equilibrium curve and thus the sample is moderately distributed, which indicates the homogeneity of the individuals of the sample under study. .

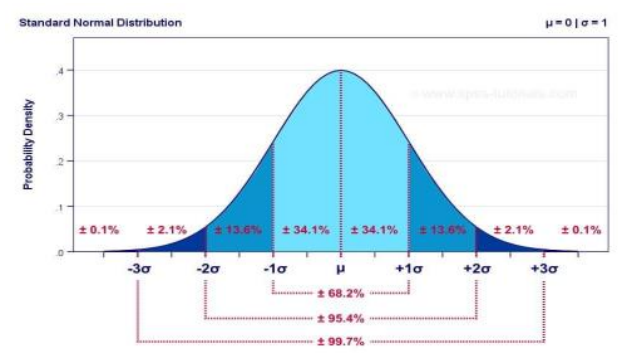

Figure (1)

Moderation of data for the research sample within the equilibrium curve between $(-3,+3)$

\section{search tools :}

First: Reference Survey Method:

The researcher has reviewed, to the best of his ability, scientific literature and previous Arab and foreign studies, with the aim of determining the following:

1. Define the general framework of the search.

2. Determine the most appropriate tests for brain control, harmonic abilities, and level of performance.

After the researcher conducted a reference survey of many previous scientific references, studies and research related to the subject of the research to identify the compatibility tests, the scale of brain control and the level of performance of the set of exercises, he presented these tests to a group of experts to ensure the suitability of these tests to the nature of the research.

In light of specialized studies and references, the following tests were chosen: -

- First, News of Harmonious

Capabilities, Issue of Hazem Ahmed Muhammad Sayed (2010)

1- The ability to assess conditions.

2- The ability to connect dynamically.

3- The ability to maintain balance.

4- Rhythmic ability.

5- The ability to adapt to changing situations.

- Scientific parameters of the tests:

Assiut Journal For Sport Science Arts 
To ensure the validity of the tests, the researcher used the validity of the terminal comparison between the upper and lower quartiles. He also

Table (2)

Indication of the differences between the upper and lower quartile For the physical tests in question $\mathrm{N}=9$

\begin{tabular}{l|c|c|c|c|c|l}
\hline \hline \multirow{2}{*}{ Variables } & \multirow{2}{*}{$\begin{array}{c}\text { Measruing } \\
\text { unit }\end{array}$} & \multicolumn{2}{|c|}{$\begin{array}{c}\text { Upper } \\
\text { Quartiles }\end{array}$} & \multicolumn{2}{|c|}{$\begin{array}{c}\text { Lower } \\
\text { Quartiles }\end{array}$} & \multirow{2}{*}{ T } \\
\cline { 3 - 6 } & & M1 & S1 & M2 & S2 & \\
\hline \hline assess situations & Degree & 5.31 & 1.63 & 2.21 & 1.25 & 7.34 \\
\hline Dynamic link & Accurate & 1.75 & 2.12 & 3.65 & 1.88 & 8.43 \\
\hline maintain balance & Degree & 24.43 & 1.94 & 16.99 & 2.95 & 9.51 \\
\hline Rhythmic ability & Degree & 55.78 & 1.27 & 34.52 & 0.55 & 6.35 \\
\hline $\begin{array}{l}\text { adapt to changing } \\
\text { situations }\end{array}$ & Degree & 53.68 & 1.86 & 34.27 & 1.51 & 10.42 \\
\hline \hline
\end{tabular}

The value of (T) to denote the two sides at a level of (0.05)

It is clear from Table (2) that there are statistically significant differences between the upper quartile and the lower quartile in the physical tests under investigation and in

Table (3)

Correlation coefficients between the first and second applicationsFor the compatibility tests under consideration $\mathrm{N}=9$

\begin{tabular}{l|c|c|c|c|c|l}
\hline \hline \multirow{2}{*}{ Variables } & \multirow{2}{*}{$\begin{array}{c}\text { Measruing } \\
\text { unit }\end{array}$} & \multicolumn{2}{|c|}{ First test } & \multicolumn{2}{|c|}{ second test } & \multirow{2}{*}{ Correlation } \\
\cline { 3 - 6 } & $\mathrm{M} 1$ & $\mathrm{~S} 1$ & $\mathrm{M} 2$ & $\mathrm{~S} 2$ & \\
\hline \hline $\begin{array}{l}\text { Assess } \\
\text { situations }\end{array}$ & Degree & 3.76 & 1.44 & 3.97 & 1.77 & 0.89 \\
\hline Dynamic link & Accurate & 2.70 & 1.89 & 2.84 & 2.42 & 0.81 \\
\hline $\begin{array}{l}\text { maintain balance } \\
\text { Rhythmic ability }\end{array}$ & Degree & 20.71 & 2.445 & 20.22 & 1.78 & 0.90 \\
\hline $\begin{array}{l}\text { adapt to } \\
\text { changing } \\
\text { situations }\end{array}$ & Degree & 45.15 & 0.91 & 45.24 & 1.65 & 0.80 \\
\hline \hline
\end{tabular}

The tabular value $(\mathrm{C})$ at the level (0.05)

Assiut Journal For Sport Science Arts favor of the higher quartile with significant significance 0.05 , which gives a direct indication of the validity of these tests. 
It is clear from Table (3) the correlation coefficients between the first and second test of the harmonic abilities tests under consideration, which ranged between (0.90: 0.81 , which are statistically significant correlation coefficients, which indicates the stability of the results of these tests.

\section{Second, the Cerebral Control Scale, by Tariq Badr Al-Din (2015):}

The scale consists of (26) phrases describing the behaviors that the subject follows in training or competition situations and through his dealings and sports life with others, in addition to his feelings, responses and ideas about himself.

The subject responding to the scale statements by choosing one of the answers (a) or (b) that expresses his personal opinion and describes his feeling.

\section{Correct the scale:}

The

respondent's responses to the phrases (a) are collected separately and his response to the phrases (b) separately, and if the number of responses to the phrases (a) is greater than (b) the person who responds to that response is distinguished by the right pattern and vice versa, and if the test scores are equal, i.e. he gets (13) A degree in (a) or (b) distinguishes the subject with mixed type. (Attachment)

Scientific transactions of scale:

The researcher conducted the psychometric analysis of the scale using the following methods and methods:

\section{First: Verify the scale:}

The researcher used two methods to calculate the validity of the scale, the first being the validity of the arbitrators, by presenting the scale to the experts, and the approval rate of the arbitrators on the scale as a whole was $100 \%$ and the statements were $80 \%$ as a minimum for approval of the statements.

The researcher also used the honesty associated with the test, as the researcher applied the brain control test (Diane2005), which he translated into Arabic and extracted his scientific parameters (Qadoumi 2010) on the exploratory sample, consisting of (20) students from the research community and outside the research sample, and the correlation coefficients were calculated between the average scores of the students In the two scales, and the following table shows that. 
Table (4)

Correlation coefficients between the mean of the survey sample scores In the cerebral control test and cerebral control scale $\mathrm{N}=9$

\begin{tabular}{l|c|c|c}
\hline \hline \multicolumn{1}{c|}{ Variables } & Mean & $\begin{array}{c}\text { Standard } \\
\text { deviation }\end{array}$ & Correlation \\
\hline \hline Diane's cerebral control & 10.7 & 3.20 & \multirow{2}{*}{$* 0.891$} \\
\hline Brain control of Tariq Badr al-Din & 11.14 & 3.24 & \\
\hline \hline
\end{tabular}

The tabular "C" value at the level of significance $0.05=0.66$ It is evident from Table (4) that there is a statistically significant correlation relationship between the results of the two tests at a significant level of 0.05 , where the calculated value of (r) was greater than the tabular value of $(\mathrm{t})$, which indicates the validity of the scale of cerebral control under investigation.

Second, stability of scale: applications. calculated the test stability using the Tast \& Retast method by applying the test to an exploratory sample consisting of (9) students from the study population and outside the basic sample, then re-applying it again a week after the first application, and the following table shows the correlation coefficient Between the two

Table (5)

Simple correlation coefficient between application and re-application $\mathrm{N}=9$

\begin{tabular}{c|c|c|c|c|c}
\hline \hline \multirow{2}{*}{ Variables } & \multicolumn{2}{|c|}{ First test } & \multicolumn{2}{c|}{ second test } & \multirow{2}{*}{ Correlation } \\
\cline { 2 - 5 } & M1 & S1 & M2 & S2 & \\
\hline \hline Cerebral control & 11.14 & 3.24 & 11.89 & 3.21 & 0.89 \\
\hline \hline
\end{tabular}

The tabular " $t$ " value is at degrees of freedom (7) and the significance level of $0.05=0.66$

It is evident from Joule

(5) that there is a correlation between application and reapplication of the cerebral control test under study, as the calculated (r) value is greater than the tabular $(\mathrm{t})$ value at 0.05 significance. Which gives a direct indication of the reliability of the results of this test .

Study application steps: -

Preliminary stage: -

Conducting the pilot study:

The exploratory study was conducted on (9) students from the research community and outside the original 
sample. The study aimed at the following: -

- Knowing the correct methods of conducting measurements in practice.

- Ensuring the validity of the devices and tools used in the search procedures

- Identify the problems that the researcher may face during the application

- Being assured of the accuracy of measurements for each variable.

Ensure the specified time period for each educational unit.

The results of the pilot study have resulted in the achievement of all its objectives.

Measurements and tests of the variables under consideration:

\section{Pre-analogy: -}

The

researcher

conducted a pre-measurement on the research sample on Monday and Tuesday $8 / 9 / 10 / 2018$, as the cerebral control scale was applied on Monday, and the tests of harmonic abilities and performance level were carried out on Wednesday.

\section{The proposed program: -}

The proposed educational program was implemented in the proposed construction method using a set of tools (such as the stick, box, ropes, wooden ladders), starting on Sunday 14/10/2018, which lasted for a period of (8) weeks with (4) training units per week, average time Unity in the week $(60 \mathrm{~m})$, during the following days (Sunday, Monday, Wednesday, Thursday) of each week ending on Thursday 13/12/2018.

\section{Program planning:}

Before developing the program, the goal of it must be determined and the foundations to be followed when developing the program, which is to identify the elements of the structural method, which depends on the student's participation in the educational process and making it the focus of the educational process and his participation in the basic goal of research, developing the pattern of brain control and improving students 'ability to perform Kinetic groups for exercises in the left and right direction with the same efficiency through the use of a set of tools.

\section{The aim of the program:}

The aim of the educational program in the constructive method is to develop the pattern of brain control and to identify its effect on the harmonic abilities and 
the level of performance of the set of exercises among students of the major (the research sample)
Time distribution of the educational program: -

Table (6)

\begin{tabular}{l|c}
\hline \multicolumn{1}{c|}{ Aim } & $\begin{array}{c}\text { Suggested exercise program } \\
\text { Development of the cerebral control }\end{array}$ \\
\hline \hline Number of weeks & 8 weeks \\
\hline Number of units per week & 4 \\
\hline Repetition & $(7: 10)$ Depending on the nature of the exercise \\
\hline Groups & $\mathrm{G}) 8-5($ \\
\hline Comfort between groups & $(3: 5) \mathrm{m}$ \\
\hline Rest time for the unit group & $(30 \mathrm{~S}: 1 \mathrm{M})$ \\
\hline \hline
\end{tabular}

Time planning for the Total time for the program
proposed educational

program:

- The period of the training program: for a period of (8) weeks from Sunday $10 / 14 / 2018$ to Thursday $12 / 13 / 2018$, with four training units per week.

Number of training units per week: -

(4) training units per week, days (Sunday - Monday Wednesday - Thursday), the time of the study unit: (60) minutes.

Number of units during the implementation period of the program:

- 4 units $\times 8$ weeks $=32$ training units.

Total time per week:

- 4 units $\times 60$ minutes $=$ 240 minutes $=4$ hours.

\section{under discussion:}

- 8 weeks x $4=32$ hours

Foundations for setting up the program:

Before preparing the program, the researcher took into account the foundations on which the program is based and the characteristics of this stage, so that the appropriate program can be built using different tools that can be used in the left and right direction such as ropes, boxes, wooden ladders and plumbing, in order to improve the pattern of brain control of the sample under study. The following principles are defined as criteria for the program:

- Follow the principle of diversity in using different exercises. 
Follow the principle of gradual exercise in choosing exercises from easy to difficult and from simple to complex, as well as with regard to the intensity of the training load.

- Apply the principle of positive comfort.

- Regular training without interruption.

- Taking into account the security and safety factors throughout the program implementation period.

- Follow the method of conducting pilot experiments to determine the starting doses and the intensity of the training pregnancy.

- Follow the principle of individual differences in the program for each student.

\section{the final level :-}

\section{Dimensional measurement: -}

The post-measurement was performed on the research sample under the same conditions as the premeasurement application, on Sunday and Monday 12/17/16/2018.

\section{Statistical treatments: -}

The researcher used statistical treatments appropriate to the nature of the research, which included: -

(Arithmetic mean, standard deviation, torsion, variance $\mathrm{T}$ test, Passron simple correlation coefficient, improvement)

Presentation and discussion of results: -

Firstly display results:

Table (7)

Indication of differences Right and left in the pre and post measurements we have the research sample $N=20$

\begin{tabular}{l|c|c|c|c|c}
\hline \hline \multirow{2}{*}{ Variable } & \multicolumn{2}{|c|}{ Left style form } & \multicolumn{2}{c|}{ Right style form } & \multirow{2}{*}{ T } \\
\cline { 2 - 6 } & M1 & S1 & M2 & S2 & \multirow{2}{*}{$* 7.35$} \\
\hline \hline $\begin{array}{l}\text { Measurement before } \\
\text { the program }\end{array}$ & 11.08 & 1.295 & 14.95 & 2.09 & 1.64 \\
\hline $\begin{array}{l}\text { Measurement } \\
\text { after the program }\end{array}$ & 13.19 & 2.225 & 12.81 & 1.53 & 1.64 \\
\hline \hline
\end{tabular}

The tabular T significance level is at 0.05 level of significance

It is evident from Table

(7) that there are statistically significant differences between the right type and the left type of the brain control scale in the pre-measurement research sample and in favor of the right type, as the calculated (T) value is greater than the tabular (T) value at a significant level (0.05) , Which indicates that the research sample is 
characterized by the right brain control pattern in the premeasurement, while there are no statistically significant differences between the right type and the left type of the brain control scale in the research sample in the post- measurement research sample, as the calculated $(\mathrm{T})$ value is less than the $(\mathrm{T})$ value. The tabularity is at a significant level (0.05), which indicates that the research sample is characterized by a mixed brain control pattern (right, left).

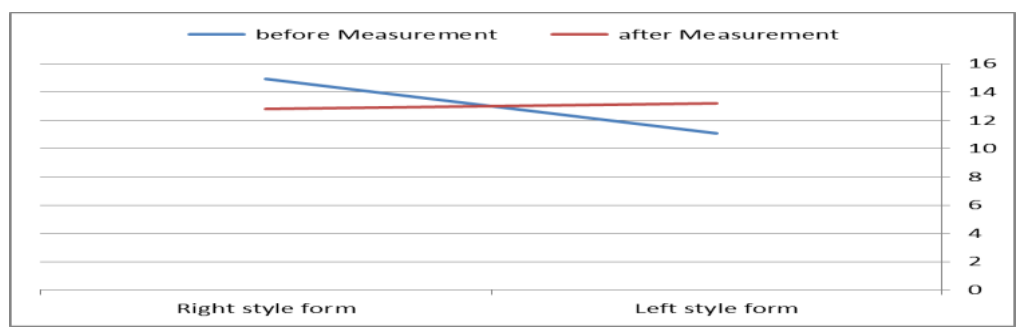

\section{Diagram (2)}

The differences between the two types of cerebral control

\section{Table (8)}

The left and right in the measurements before and after the research sample.

\section{Indication of differences pre-measurement and post-measurement} for the research sample In tests of harmonic abilities under investigation $\mathrm{N}=\mathbf{2 0}$

\begin{tabular}{l|l|c|c|c|c|c|c}
\hline \hline \multirow{2}{*}{$\mathbf{N}$} & \multirow{2}{*}{ Variables } & \multirow{2}{*}{$\begin{array}{c}\text { Measruing } \\
\text { unit }\end{array}$} & \multicolumn{2}{|c|}{$\begin{array}{c}\text { Measurement } \\
\text { before the program }\end{array}$} & \multicolumn{2}{c|}{$\begin{array}{c}\text { Measurement after } \\
\text { the program }\end{array}$} & \multirow{2}{*}{ T } \\
\cline { 4 - 7 } & & & $\mathbf{M 1}$ & $\mathbf{S 1}$ & $\mathbf{M 2}$ & $\mathbf{S 2}$ & \\
\hline \hline 1 & assess situations & Degree & 4.12 & 0.84 & 4.92 & 0.96 & $10.32 *$ \\
\hline 2 & Dynamic link & Accurate & 2.25 & 0.49 & 1.52 & 0.84 & $* 11.12$ \\
\hline 3 & maintain balance & Degree & 19.24 & 2.93 & 24.91 & 3.51 & $* 9.25$ \\
\hline 4 & Rhythmic ability & Degree & 46.17 & 1.16 & 50.88 & 5.24 & $* 5.95$ \\
\hline 5 & $\begin{array}{l}\text { adapt to changing } \\
\text { situations }\end{array}$ & Degree & 45.53 & 2.17 & 51.51 & 2.04 & $* 7.45$ \\
\hline \hline
\end{tabular}

The tabular T significance level is at 0.05 level of significance

It is evident from Table

(8) that there are statistically significant differences between the pre-measurement and the post-measurement for the research sample in the compatibility tests under consideration, as the calculated value of $(T)$ is greater than the tabular value of $(\mathrm{T})$ at a significant level of (0.05). 


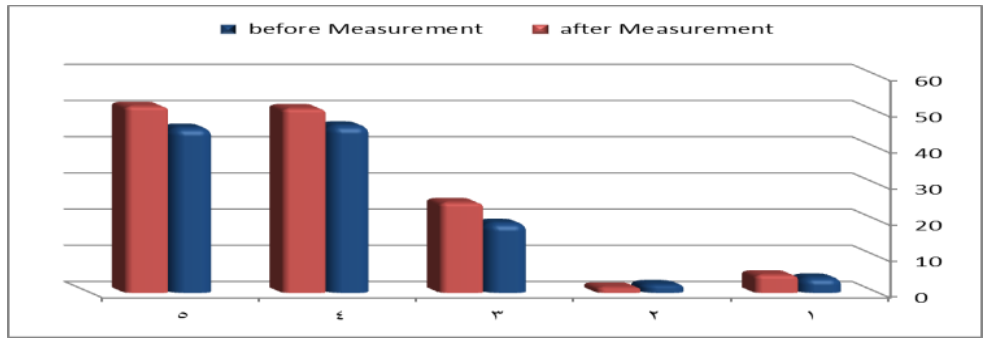

\section{Diagram (3)}

Differences pre-measurement and post-measurement for the research sample In tests of

harmonic abilities under investigation

Table (9)

Indication of differences pre-measurement and post-measurement for the research sample In the performance level of the exercises $N=20$

\begin{tabular}{|c|c|c|c|c|c|}
\hline \multirow{2}{*}{ Variable } & \multicolumn{2}{|c|}{$\begin{array}{c}\text { before } \\
\text { Measurement } \\
\end{array}$} & \multicolumn{2}{|c|}{$\begin{array}{c}\text { after } \\
\text { Measurement }\end{array}$} & \multirow[t]{2}{*}{$\mathbf{T}$} \\
\hline & M1 & S1 & M2 & $\mathbf{S 2}$ & \\
\hline $\begin{array}{l}\text { The level of } \\
\text { performance of } \\
\text { whole exercise }\end{array}$ & 5.25 & 1.94 & 7.95 & 1.21 & 12.64 \\
\hline
\end{tabular}

The tabular T significance level is at 0.05 level of significance

It is evident from Table under consideration, as the

(9) that there are statistically calculated value of $(\mathrm{T})$ is significant differences between the pre-measurement and the post-measurement for the research sample in the level of performance of the set of exercises

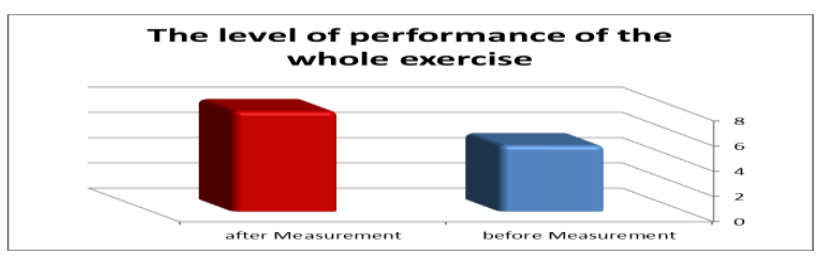

\section{Diagram (4)}

Differences of pre-measurement and post-measurement for the research sample In the level of performance of the whole exercise 
Table (10)

Percentage improvement between the pre and post measurements In the harmonic abilities and the level of the set of exercises $N=20$

\begin{tabular}{c|c|c|c|c|c}
\hline \hline $\mathbf{N}$ & Variables & $\begin{array}{c}\text { before } \\
\text { Measure } \\
\text { ment }\end{array}$ & $\begin{array}{c}\text { after } \\
\text { Measure } \\
\text { ment }\end{array}$ & Diff & $\begin{array}{c}\text { Percenta } \\
\text { ge }\end{array}$ \\
\hline \hline & assess situations & 4.12 & 4.92 & 0.81 & $\% 19.54$ \\
\hline$r$ & Dynamic link & 2.25 & 1.52 & 0.73 & $\% 32.4$ \\
\hline$r$ & maintain balance & 19.24 & 24.91 & 5.67 & $\% 29.47$ \\
\hline $\boldsymbol{\varepsilon}$ & Rhythmic ability & 46.17 & 50.88 & 4.71 & $\% 10.2$ \\
\hline 0 & $\begin{array}{c}\text { adapt to changing } \\
\text { situations }\end{array}$ & 45.53 & 51.51 & 5.98 & $\% 13.13$ \\
\hline $\mathbf{T}$ & $\begin{array}{c}\text { The level of } \\
\text { performance of } \\
\text { the whole exercise }\end{array}$ & 5.25 & 7.95 & 2.7 & $\% 51.43$ \\
\hline
\end{tabular}

Table (10) shows the percentage improvement between the pre and post measurements in the harmonic abilities and the level of the total exercises under discussion.

\section{Diagram (5)}

Percentage improvement between the pre and post measurements

In the harmonic abilities and the level of the set of exercises Discuss the results

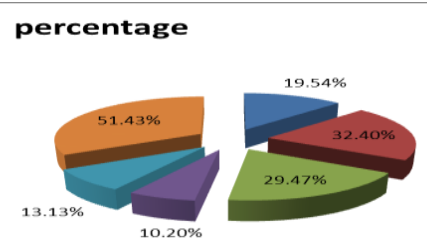

Discussion of the first hypothesis:

It is evident from Table (7) that there are statistically significant differences between the right type and the left type of the brain control scale in the 
pre-measurement research sample and in favor of the right type, as the calculated (T) value is greater than the tabular (T) value at a significant level (0.05) , Which indicates that the research sample is characterized by the right brain control pattern in the premeasurement, while there are no statistically significant differences between the right type and the left type of the brain control scale in the research sample in the postmeasurement research sample, as the calculated $(\mathrm{T})$ value is less than the (T) value. Tabular at a significant level (0.05), which indicates that the research sample is characterized by a mixed brain control pattern (right, left) in the post-measurement, and this is what Figure (2) illustrates, which shows the convergence of the left and right brain control pattern in the dimensional measurement, while the differences vary Among them is in the premeasurement, and the researcher attributes this improvement in the pattern of cerebral control and its shift from the right mode to the mixed mode of cerebral control, to the proposed educational program in the structural method, where the program included the use of some tools (stepping box, ropes, ladder, balls) Where the aim of their use is to focus on the left and right directions of the research sample, and the exercises used were taking in their form sports performances, which contain a group of exercises that the student saves in the form of (8) repetitions for each movement sentence, whether in the right or left direction, which It helps in linking the dynamic to the students in the left and right directions, as well as their compatibility with the music greatly helps in the process of activating the mental processes associated with the pattern to be activated and this is consistent with what was mentioned by " Khattab,Attiyat and Zahra, Lily (1997) that exercise contributes to mental education for the participants about By memorizing the various movements that are included in the show, and what the show requires of linking the movements between each other and between the movements and the music helps to develop the speed of thinking, good behavior and speed of response among the players., And also agrees with Loran and peter 
ferancais (1990) that among the tools used in the step aerobic box or the training box which It is considered one of the training methods, which depend on moving up and down to and from a box, controlling and controlling performance against and with the Earth's gravity in perfect agreement between the work of the upper, lower, right and left limbs of the body, and the researcher believes that it is the most important thing that contributed to the improvement of the brain control pattern of the research sample and its transformation To the mixed mode is the reliance on the elements of constructive learning such as (advocacy and discovery, suggesting interpretations and solutions, then making decisions), which is the most important characteristic of constructive learning, and this is what was referred to by Ali Abdul Majeed (2001). The Constructivism learning modal model is one of the most prominent models Which depends on constructive thought through the four stages (advocacy, discovery and exploration, proposing interpretations and solutions, taking measures). In this model, learners are helped to build their scientific concepts and knowledge based on their previous experiences, as well as link science to mastery in society.

Also, constructive learning is focused on the learner through his dialogue with the teacher to reach solutions and proposals, which is the most important thing that helps the researcher in how to identify the most appropriate exercises that are suitable for the research sample according to the type of brain control. These results and this is what was confirmed by Zaitoun Hassan and Zainoun Kamal (2003) that the constructive learning method is one of the learner-centered teaching methods rather than being teacher-centered. It is also worth noting that the constructive learning method seeks to learn new knowledge through its construction. By themselves, this learning is meaningful for them and relevant to their working life. It also seeks to develop the learners' ability to self-learning through the development of learning processes from or scientific research they have, including (processes of observation - comparison - 
generalization - conclusion).

Through the previous presentation and in light of the research objectives, the first hypothesis was fulfilled, which stated that "there are statistically significant differences between the two types of brain control (right and left) in the research sample in the pre-measurement, while there are no differences between them in the postmeasurement."

\section{Discussion of the second hypothesis:}

It is evident from Table

(8) that there are statistically significant differences between the pre-measurement and the post-measurement in the research sample in the compatibility tests under consideration, as the calculated value of $(T)$ is greater than the tabular value of $(\mathrm{T})$ at a significant level (0.05), as it is explained Table (10) The improvement rates in the harmonic abilities between the pre-measurement and the postmeasurement, where the differences in the rates of change were in the "ability to change situations" test (19.54\%), the "ability to link movement" test $(32.40 \%)$ and in the "ability to balance" test. $(29.47 \%)$ and the "rhythmic ability" test (10.20\%) and the "adaptation to changing conditions" test $(13.31 \%)$, and this is what Figure (3) explains, which shows the differences in graphical columns between the pre-measurement and the postmeasurement of the research sample in the level of harmonic abilities A clear superiority is evident in the postmeasurement, as shown in Table (9) that there are statistically significant differences between the premeasurement and the postmeasurement in the research sample in the level of performance of the set of exercises under consideration, as the value of $(\mathrm{T})$ calculated is greater than the value of $(\mathrm{T})$ table. At a significant level (0.05), this is evident from Table (10) and Figure (5) for the percentage improvement in the level The performance of all exercises between the premeasurement and the postmeasurement, where the differences in the improvement rates reached $(51.4 \%)$. The researcher attributes these differences and the aforementioned improvement rates to the educational program used in the structural method according to the proposed type of brain control, 
which was deliberately developed to develop the mixed pattern of cerebral control. Directly on harmonic abilities as it is characterized by accuracy with energy saving, such as the ability to change conditions, retention ability and motor linkage, and this is consistent with what Jerzy Sadoskil (2005) indicated that harmonic abilities are important in sports activity as they play a major role in accuracy and economics from Sports movements under changing circumstances also contribute to speed and accuracy in expected and unexpected movements. Wafaa Abdel Hafeez (2005 CE) emphasized that the development of harmonic abilities affects the mastery of the skillful performance of the practicing sports activity as this is consistent with what was indicated by " Farid Khaled (2007). That the harmonic abilities are one of the most important factors necessary to raise the level of technical performance of the players, as it stems from the qualitative analysis of the specialized sports activity. Its growth and development greatly serves the technical side, and the harmonic abilities are one of the means of controlling and controlling the various motor performances, and then the availability of these capabilities among the players enables them to reach the best levels of compatibility of the performance required to accomplish any movement performance and these results are consistent with the results of any study. AbdelGhani,Abeer (2014), who concluded that the use of the exercise program used had a positive effect in improving some of the harmonic abilities of the research sample. The researcher also believes that the most important feature of the proposed exercise program is that it included a group of different tools that helped improve the level of performance, and this is consistent with this. With the study " Mahmoud Nevin (2013), which concluded that the use of tools in training programming helped improve the skill performance of judo players.

Through the previous presentation and in light of the research objectives, the second hypothesis was fulfilled, which states that:

"There are statistically significant differences between 
the pre-measurement and the post-measurement in the research sample, in terms of harmonic abilities and the level of performance of the set of exercises in favor of the postmeasurement."

\section{Conclusions:}

Within the limits of the objectives, assumptions, and procedures of the research and the presentation and discussion of the results, the researcher reached the following conclusions:

1- The use of constructive learning in learning the set of exercises positively influenced the development of the pattern of brain control And his conversion to mixed mode is under discussion.

2- The use of constructive learning according to the pattern of brain control, the effect of improving the harmonic abilities.

3- The use of constructive learning according to the pattern of brain control has an effect on improving the performance of all exercises.

\section{Recommendations:}

Based on the results of the research, the researcher recommends the following:

1- Using the constructive learning method in learning motor courses.
2- Interest in developing the brain-control pattern into a mixed mode.

3- Paying attention to developing consensus capabilities because of their clear impact on the level of performance.

\section{References: -}

Firstly, Arabic references:

1- Salary, Osama Full (1990):

Motives for excellence in sporting activity, Dar Al Fikr Al Arabi, 1st Edition, Cairo.

2- Faghry ,Ayham Abu Mujahid Al-

Neuropsychology and learning difficulties, Al-Baramkeh, Damascus University

3- Ali , Jamil Khadr (2015): The effect of rope-jumping exercises accompanied by music on anaerobic capacity pulse rate - reaction speed time among female students of the Faculty of Physical Education, Salah al-Din University, Erbil, second phase, Journal of Physical Education Sciences, College of Physical Education, University of Babylon.

4- Zeitoun, Hassan Hussein, Zaitoun ,Kamal Hussein (2003) Learning and teaching from the perspective of constructivist theory, world book

5- Shehata ,Hassan Muhammad (1998): Curriculum between 
theory and practice; Al-Orouba Book House Cairo

6- Majeed, Saleh Abdul Aziz Abdel (1996): Education and Teaching Methods House of Knowledge; part One ; Cairo 7- El-Ghadoury, Abdel Nasser Abdel-Rahim (2010): Brain Control of Football Players in Palestine, Journal of Educational and Psychological Sciences, Eleventh Volume, Fourth Issue, College of Physical Education, University of Bahrain,

8- Al-Khaleq, Issam Abd (1992): Sports Training, Theories and Applications, Arab Thought House, Cairo

9.

Khattab,

Attiyat Muhammad and others (2006): Basics of exercises and rhythmic exercises, first edition Arab Thought House, Cairo

10- Majeed, Ali Muhammad Abd al- (2001): A proposed strategy based on the Blearning model and its effect on the motor innovation of primary school pupils; published research; Scientific Journal of Physical Education and Sports, College of Physical Education; Helwan University 11- Zaitoun, Kamal AbdelHamid (2003): Teaching science to understand a constructive vision (The World of Books, Cairo

12- Zaghloul, Mohamed Saad (2002): Educational technology and its methods in physical education, Book Center for publication, cairo

\section{3- Yusri Muhammad} Hassan (2010): The effect of a program of exercises using tools on improving the level of compatibility abilities of junior tennis players from 9-12 years old, Journal of Physical and Sports Floating, College of Physical Education, Menoufia University.

Secondly, foreign references: 14- Dibi, p, scott, R ( 1996 ): fitness stepping, human kinetics, publishers inc . international perspectives in physical education and sport coaching

15- Jensen (2001):

Brain Based learning .Stor San Diego,CA USA,

16- Irem duzgun, gul baltaci ,fifiz colakoglu,Volga bayrakci (2010): The Effects of JumpRope Training on Shoulder Isokinetic Strength in Adolescent Volleyball Players, in Journal of Sport Rehabilitation

17- Loran and peter ferancais (1990): physical and biomechanical effects of stepping with the effects of thestera ditional activities sending state university

18- Raczek. J (2005): Learning and coordination skills. Rivista culture sportive, Roma.

19- Sousa, D., (2001): How The Brain Learns, Reaton, VA, National Association Of Secondary School Principals Soraya Nafeh, Book Center for Publishing 